AperTO - Archivio Istituzionale Open Access dell'Università di Torino

\title{
A Concise History of Thiopurines for Inflammatory Bowel Disease: From Anecdotal Reporting to Treat-to-Target Algorithms
}

This is a pre print version of the following article:

Original Citation:

Availability:

This version is available http://hdl.handle.net/2318/1692645

since 2019-02-15T15:29:20Z

Published version:

DOI:10.2174/1574887113666180910120959

Terms of use:

Open Access

Anyone can freely access the full text of works made available as "Open Access". Works made available under a Creative Commons license can be used according to the terms and conditions of said license. Use of all other works requires consent of the right holder (author or publisher) if not exempted from copyright protection by the applicable law. 
Manuscript Type: MINIREVIEW

A Concise History of Thiopurines for Inflammatory Bowel Disease: from Anecdotal Reporting to Treat-toTarget Algorithms

Running title: Thiopurines and Inflammatory Bowel Disease

*Giovanni Clemente Actis, Rinaldo Pellicano, Davide Giuseppe Ribaldone

Giovanni Clemente Actis, The Medical Center Practice Office, Turin, Italy

Rinaldo Pellicano, Unit of Gastroenterology, Molinette Hospital, Turin, Italy

Davide Giuseppe Ribaldone, Department of Medical Sciences, University of Turin, Italy

ORCID number: Giovanni Clemente Actis (0000-0001-7807-557X), Rinaldo Pellicano (0000-0003-3438-0649), Davide Giuseppe Ribaldone (0000-0002-9421-3087)

*Correspondence to: Giovanni Clemente Actis, MD, The Medical Center, Corso Einaudi 18 a, 10129 Turin, Italy. Actis_g@libero.it

Telephone: + 39-011-591388

Fax: + 39-011-505564 


\section{Abstract}

Background: The need for immune suppressive strategies in the control of chronic inflammatory bowel diseases originated in the 1960s following the perception of a relative inefficacy of salazopyrin and its derivatives. In some 50 years upon an anecdotal claim, the indication for thiopurines in the management of inflammatory bowel diseases has come of age.

Objective: The aim of this minireview is to give an overview, after the historical premises, of the current use of thiopurines in the context of inflammatory bowel diseases.

Method: Through MEDLINE searches, we reviewed the literature of the last two decades.

Results: For Crohn's disease, the 1980 trial of 6-mercaptopurine for steroid sparing and fistula closure proved pivotal. The analysis of withdrawal experiments and of numerous open trials have established the efficacy of thiopurines for ulcerative colitis. In this indication, cutting-edge data are now showing that because targeting dysplasia, thiopurines can induce mucosal/histological healing, thus abolishing or delaying the need for pre-emptive (tumor prophylactic) colectomy.

Conclusion: In UC thiopurines may be recognized to effect a treat-to-target strategy, joining the modern algorithms of rheumatologic disorders.

Key words: Thiopurines, Inflammatory Bowel Disease, Ulcerative colitis, Treat-to-Target, Crohn's Disease, Azathioprine, Mercaptopurine 


\section{Introduction}

At the time when the Western World appears to become indwelled by chronically inflamed individuals ("the inflammacitizens") [1], the inflammatory disorders of the bowel have begun to trespass the Western boundaries, invading the East with epidemics-like episodes in hitherto unsuspected areas, such as for example the Persian counties [2].

The consequent hustle to refine effective remedies has revealed that the Achilles heel in the treatment of inflammatory bowel diseases (IBD) relies with a relative lack, and/or scarce effectiveness of drugs to maintain remission [3]. Begun sometime in the 40s, the chase for drugs capable to maintain an effective, yet acceptably toxic control of IBD, was initially rewarded by the release of salazopyrin [4] and its mesalamine derivatives [5]. However, despite continuous improvements, mesalamines have revealed substantial limits, including an unsatisfactory control of severe ulcerative colitis (UC) [6], weak activity in Crohn's disease (CD) [7], a low but documented tendency to be nephrotoxic [8].

IBD is known to mainly present with an acute bout that then tends to settle in a variable time length. Chronicization of inflammation may be hypothetically ascribed to a plethora of often intertwined factors, schematically including: 1) mucosal damage induced by reactive oxygen species as by-products of the uncoupling of mitochondrial oxidative phosphorilation [9]; 2) altered mucosal permeability [10]; 3) genetic biases towards pro-inflammatory cytokine networks, promoting a crucially pathogenetic dialogue error between luminal contents and mucosal immune system [11]. Naturally occurring regulators of such pro-inflammatory forces do exist, including the action of regulatory T-lymphocytes (T-regs) [12], the preferential gut use of antibodies that do not fix complement [13], and the defensive role played by mucus and defensins [14]. If prevailing, these factors may cause abortion of the gut inflammatory chain, originating the clinical entity called by some "self-limiting colitis" [15]. However, failure is not uncommon as witnessed by commonly reckoned data on the natural history of UC: a 50-80\% frequency of a swinging course, whereas $15-30 \%$ of the patients experiences a chronic active course [16] leading to a $10 \%$ resort to surgery after 5 years [17]. Often exhibiting an erratic or continuous steroid dependence, such patients were classified as indications for long-run immune suppressive regimes by International Organizations [18]. Reassured by the extensive rheumatologic experience, a few caretakers adhering to the recommendations borrowed methotrexate (MTX) from their rheumatologist pairs to try and maintain remission in their IBD subjects [19]. The results of a few trials indicate that MTX can achieve and maintain remission in some CD patients [20]; however, its probable inferiority to thiopurines rarely recommends its indication as a first-line drug, unless in CD patients with a dominant rheumatologic presentation [21]. No reliable data are so far available on the effectiveness of MTX in UC; last but not least, the liver toxicity of MTX (fibrosis) is an important issue [22]. The complex of this data therefore advises us to shift our consideration to the thiopurines. 
In the 60s, the thiopurines (azathioprine / 6-mercaptopurine) sneaked through these "glitches" to enter the arena of the treatment of IBD.

The aim of this minireview is to give an overview, after the historical premises, of the current use of thiopurines in the context of IBD.

Articles published in English on the use of thiopurines in patients with IBD were identified through MEDLINE, SCOPUS, ISI-Web of Knowledge, and EMBASE searches using the terms "IBD", "inflammatory bowel disease", "ulcerative colitis", "Crohn’s disease", "thiopurines", "maintenance therapy”, "immune suppression", "6-mercaptopurine” and "azathioprine". The start date was 1980 and the final date of the search was April 15, 2018. Reference lists from published articles were also employed. Titles of these publications and their abstracts were scanned in order to eliminate duplicates and irrelevant articles. Two authors (G.C.A. and D.G.R.) independently reviewed the literature search' results and selected relevant studies. The full-text studies were assessed by the two authors to determine whether the inclusion criteria were met (Figure 1).

Figure 1 Study screening and selection.

\subsection{Thiopurine Metabolism}

The thiopurines are purine analogues that were initially proposed by the Nobel Prize winners Elion and Hitching for the treatment of hematologic malignancies [23].

For short, the pro-drug azathioprine (AZA) undergoes non-enzymatic conversion to the active molecule 6mercaptopurine (6-MP) at the liver level. A number of horizontal steps then metabolize 6-MP to 6-thioguanine nucleotide (6-TGN), the effectors of the cytoreductive actions at the basis of the original hematologic indications of the thiopurines. Two crucial side-pathways governed by thiopurine methyl-transferase (TPMT) and xanthine oxydase (XO) may respectively produce methyl-mercaptopurine (MMP) or thiouric acid. Such enzymes have been exploited as the targets of a number of effective strategies to modulate thiopurine metabolism [24].

\section{Historical Notes}


The anecdotic use of 6-MP for UC has been reported as early as 1962 [25]. For roughly 30 years, the evidence of the effectiveness of AZA/6-MP for this disorder has been based on withdrawal experiments [26].

Focusing on CD, a pivotal double-blind study by Present et al., in 1980 demonstrated the activity of 6-MP in fistula closure and steroid sparing for patients with severe disease [27]. An exhaustive overview of the indications for thiopurines in IBD has recently appeared [28].

Evidence from both exhaustive clinical practice and designed trials indicates that thiopurines are best effective if introduced soon after achieving disease remission on any "acute" drug, whether steroids, cyclosporine, or anti-Tumor Necrosis Factor (TNF) biological [29], with their full action recognizing a lag of up to 17 weeks [30]. This clinical tenet is consistent with the basic-science knowledge that thiopurines effect their immune suppressive action on a two-hit basis: the initial hit simply arrests cell mitosis, the second one then abolishes the memory T-cell pool [31]. As the consequence, early withdrawal will likely lose disease control (as shown by our own data above), whereas no signs of drug effectiveness are to be expected during the lag time. Further to such points, addition of thiopurines to acute drugs (for example steroids) and for a short bout must logically be predicted to be doomed to failure; in other words, top-down strategies are not indicated in this setting $[32,33]$. Consistently, official recommendations discourage the use of thiopurine monotherapy to achieve remission [34].

\section{Recent Approaches}

In 2009, we reported our long-term follow-up study (some patients were treated until to 201 months) showing that breakthrough phenomena were relatively infrequent $(28 \%)$ and was observed at a median time of 12 months; despite treatment, 4 colectomies were required [35]. In the same year, a large withdrawal study reported that after AZA withdrawal, a third of the patients relapsed within 12 months, half within 2 years and two-thirds within 5 years [36]. Finally, in 2015, we dealt with the issue of intolerance to AZA. We retrieved 85 AZA prescriptions for $42 \mathrm{UC}, 37 \mathrm{CD}$, and 6 miscellaneous patients. In this sample, there were 10 episodes of gastric intolerance to AZA, which were switched to 6-MP: 6 out of $10(60 \%)$ responded and tolerated the switch drug in a median follow-up of 66 months [37].

Though concentrated on UC, the results of several studies confirm the crucial role played by thiopurines in the management of the IBDs. This concept is verified in terms of numbers, wherein modern series (Table $\mathbf{1}$ and Table $\mathbf{2}$ ) indicate a sensibly increased rate of use as compared to previous data. The nature itself of the chronic inflammatory affections, namely the capacity to continuously refuel the inflammatory activity in the absence of a recognizable etiologic agent required to plan the lifelong use of drugs able to curtail few or more steps of the inflammatory process at an acceptable toxicity toll. Intriguingly, retrospective analysis of a 50-year experience, has left limited doubts as to the effectiveness of AZA/6-MP, yet duly, has opened the ground for more exciting questions; a few of these regard the 
positioning of thiopurines in the algorithms, and whether thiopurines can actually impact disease history. A one-year survey from our outpatient clinic, including 88 patients with IBD, confirmed the effectiveness of thiopurines. In fact, only the resected subjects or those with left-confined disease remained in remission without these drugs [38]. Recently, in a Swedish study, Eriksson et al. have approached the issue by uniquely comparing UC patients tolerant and intolerant to thiopurines. As the result, the robust evidence was achieved that disease history does turn out modified by the consistent use of these drugs. In fact, the cumulative probability of colectomy within 10 years was significantly higher $(\mathrm{p}<0.01)$ in intolerant (29\%) than in tolerant patients (19.5\%). A similar difference was evident considering the probability of hospital admission $(\mathrm{p}<0.01)$, the risk of progression of disease extent $(\mathrm{p}=0.07)$ and the rate of patients receiving anti-TNF therapy $(\mathrm{p}=0.03)[39]$.

The evidence from both our small series (Table 1 and Table 2) [35] and the larger withdrawal study [36] indicate that early withdrawal for toxicity specifically leads to relapse and colectomy.

Table 1 The 2009 study including 38 patients with moderate/severe ulcerative colitis: follow-up [35].

\begin{tabular}{l|l}
\hline Patients & $\mathbf{3 8}$ moderate/severe UC \\
\hline$\%$ no colectomy & 62 \\
\hline$\%$ withdrawn 1-72 months & 57 \\
\hline$\%$ continued 4-121 months & 15 \\
\hline$\%$ breakthrough & 26 \\
\hline
\end{tabular}

Table 2 The 2009 study including 38 patients with moderate/severe ulcerative colitis: perturbing events [35].

\begin{tabular}{l|l|l|l}
\hline Early Withdrawal (N:12) & Late Withdrawal (N: 10) & Breakthrough (N: 10) & \\
\hline$<7$ months & $\mathbf{7 - 1 2}$ months & $\mathbf{3 - 4 8}$ months & \\
\hline $12 / 12$ & $4 / 10$ & - & Toxicity \\
\hline $9 / 12$ & $1 / 10$ & $4 / 10$ & Colectomy \\
\hline
\end{tabular}

The clinician facing such a problem may be left with two alternatives: he/she may either begin the patient on a reduced dose (50 mg for example) to be progressively increased, or genetically test the patient's TPMT, looking for low enzyme variants at risk for leucopenia. A uniform recommendation as to this issue has not yet been released. In a previous study, 
we examined the most efficacious policies that are used to react to events impacting regular thiopurine administration, including switch to 6-MP to respond to frequent rise of AZA gastric intolerance. In particular, $60 \%$ of cases of AZA intolerance responded to switch to 6-MP [37]. Hence, a trial with 6-MP is worth doing in cases of intolerance to AZA.

\subsection{Feasibility of long-term treatments}

In the cited series the range of thiopurine exposure was between 1 and $>16$ years. Some of our patients have now received these drugs for 20 years. Full monitoring of toxicity, including rise of non-melanoma skin cancer has so far been negative $[35]$.

\subsection{Hospitalization reduction}

The ability of thiopurines to reduce hospitalization is being actively investigated. One-hundred percent of 10 patients withdrawn from AZA for intolerance or toxicity had their relapse treated in hospital. Of further 16, regularly treated with AZA after a hospitalization, 11 have then been continued on AZA with no further admissions (unpublished data).

Notably, avoidance of hospitalization and less-than expected malignancy frequency may be seen as the clinical mirror of the thiopurine -dependent mucosal healing, as discussed below.

It is highly due to acknowledge that the indication for thiopurines in IBD has shown a relentless increase in the years: the percentage figures of their use in the period 1984-2006 range between 12 and 29\% (Table 3) [40-43], in contrast with the frequency of $52 \%$ in our hands [38], and the $78 \%$ claimed in Kirschgesner et al. work [44] dating to 2009-2014.

Table 3 A list of large studies giving rates of thiopurine use and study time lags.

\begin{tabular}{l|l|l}
\hline Study Team & \% Thiopurine use & Study Period \\
\hline Margagnoni et al [40] & 12.4 & $1984-2008$ \\
\hline Saibeni et al [41] & 16 & Before 2008 \\
\hline Fraser et al [42] & 28 & $1968-1999$ \\
\hline Bardhan et al [43] & UC: 16 CD: 29 & Censored 10-2006 \\
\hline Actis et al [38] & 52 & $2008-2009$ \\
\hline Kirschgesner et al [44] & UC: 78 CD: 69 & 2009-2013 \\
Eriksson et al [39] & 25.1 & End follow-up 12-2015 \\
\hline UC: ulceratve colitis; CD: Crobn's disease.
\end{tabular}

UC: ulcerative colitis; CD: Crohn's disease. 
A stimulating discussion may derive from the hint in our unpublished series that need for hospital admission can be reduced if patients are placed on thiopurines after the initial attack. What looked like a drug's capacity to alter the disease clinical history, remained in wait for the subtle demonstration that thiopurines can achieve "tight control of objective signs of inflammation halting disease progression" [45]. Indeed, recent controlled trials have looked at mucosal healing as a measure of inflammation suppression. Post-hoc analysis of the SONIC trial (looking at anti-TNF therapy for CD) has revealed that thiopurine monotherapy can achieve mucosal healing in $19 \%$ of the cases [46]. This data has now been implemented by the recent demonstration, in UC patients, that AZA monotherapy can obtain mucosal healing in $43 \%$, and histological healing in $38 \%$ of the cases [47], meeting the unexpressed wishful thinking in Allen's paper [45], and implicating the added value that AZA monotherapy in UC can avoid or delay pre-emptive colectomy thanks to the control of otherwise unchecked dysplasia [48], achieving eventual chemoprevention [49]. Similar data are now freshly coming from Scandinavia, where the figures of thiopurine prescriptions, 7\% between 1976 and 1990, had risen to $34 \%$ in 1991 2005, whereas the indication for colectomy got restrained consensually [50].

This finding, saluted by Burton Korelitz [51] as a revitalization of thiopurines, in fact solidly hints that the old thiopurines do deserve (on the rheumatologists' footprints) to enter the list of the drugs that can pursue the treat-to-target goal in IBD. Thus, recent proposals to merely position thiopurines as ancillary drugs to reduce monoclonal anti-TNF antigenicity [52], become mitigated by such fresh findings.

Apart from this newly opened scenario, one may observe that decades after the award of the Nobel Prize to Elion and Hitchins the thiopurines do not cease to raise the attention of patients, physicians, and researchers [53].

Considering thiopurine positioning in the IBD maintenance algorithm the following considerations should be taken into account.

There is no solid evidence as to when safely discontinue thiopurines in an IBD in remission [54]. A few authors have recommended that thiopurines be continued until deliberately achieving moderate (3.5-4 white blood cells per microliter) leucopenia as the guarantee of full remission [55]; of course, this is a subjective decision that depends on physician's wisdom and skills. The weak tendency to induce certain malignancies (non-melanoma skin cancer) [56] can be monitored, and is outweighed by the ability of thiopurines to lead to mucosal healing with a chemopreventive effect on colon cancer [49]. The combination thiopurines plus biologicals is better than either alone to control the two IBD phenotypes, and thiopurines can significantly reduce formation of antibodies to the hybrid antibody protein [52]. 


\section{Conclusion}

In a world where pharmacological options for IBD treatment seem to be unavoidably dominated by biological drugs, the classic yet traditional indications for thiopurines (steroid sparing, remission maintenance, avoidance of post-operative recurrence in $\mathrm{CD}$ ) seem to become revitalized by the introduction of thiopurines into demanding treat-to-target paradigms on the rheumatologists' footsteps. For instance, these concepts may find their application in the data of the CALM study, where in patients under steroids and anti-TNF monoclonals (escalated on the basis of the Crohn's Disease Activity Index, fecal calprotectin, C-reactive protein) fared yet better when mucosal inflammation control was achieved in response to the addition of an "old" thiopurine [57].

\section{List of Abbreviations}

6-MP = 6-mercaptopurine

6-TGN = 6-thioguanine nucleotide

$\mathrm{AZA}=$ azathioprine

$\mathrm{CD}=$ Crohn's disease

$\mathrm{IBD}=$ inflammatory bowel diseases

MMP = methyl-mercaptopurine

MTX $=$ methotrexate

$\mathrm{TNF}=$ anti-Tumor Necrosis Factor

TPMT $=$ thiopurine methyl-transferase

$\mathrm{UC}=$ ulcerative colitis

$\mathrm{XO}=$ xanthine oxydase

\section{Conflict of interest}

All authors declare no conflict of interest. 


\section{Acknowledgments}

With this paper, Dr Actis wishes to cherish the memory of Dr. Daniel H. Present who mastered the use of thiopurines for IBD at Mt Sinai Hospital, New York.

\section{References}

1 Aller MA, Arias N, Fuentes-Julian S et al. Coupling inflammation with evo-devo. Med Hypothesis 2012; 78: 721-31.

2 Malekzadeh MM, Vahedi H, Gohari K et al. Emerging epidemic of inflammatory bowel disease in a middle income country: A nation-wide study from Iran. Arch Iran Med 2016; 19: 2-15.

3 Holleran G, Lopetuso LR, Ianiro G et al. Gut microbiota and inflammatory bowel disease: so far so gut! Minerva Gastroenterol Dietol 2017; 63: 373-84.

4 Watkinson G. Sulphasalazine: A review of 40 years' experience. Drugs 1986; 32: 1-11.

$5 \mathrm{Li} \mathrm{W}$, Zhang ZM, Jiang XL. Once daily vs multiple daily mesalamine therapy for mild-to-moderate ulcerative colitis: a meta-analysis. Colorectal Dis 2016; 18: 214-23.

6 Kornbluth A, Sachar DB, Practice Parameters Committee of the American College of Gastroenterology. Ulcerative colitis practice guidelines in adults (update): American College of Gastroenterology, practice parameters committee. Am J Gastroenterol 2004; 99: 1371-85.

7 Lim WC, Wang Y, MacDonald JK, Hanauer S. Aminosalicylates for induction of remission or response in Crohn's disease. Cochrane Database Syst Rev 2016; 7: CD008870.

8 Margetts PJ, Churchill DN, Alexopoulou I. Interstitial nephritis in patients with IBD treated with mesalamine. J Clin Gastroenterol 2001; 32: 176-8.

9 Biasi F, Leonarduzzi G, Oteiza PI, Poli G. IBD: mechanisms, redox considerations, and therapeutic targets. Antioxid Redox Signal. 2013; 19: 1711-47.

10 Michielan A, D’Inca' R. Intestinal permeability in IBD: pathogenesis, clinical evaluation, and therapy of leaky gut. Mediators Inflamm 2015; 2015: 628157.

11 Mitsuyama K, Matsumoto S, Masuda J et al. Therapeutic strategies for targeting the IL-6/STAT-3 cytokine signaling pathway in IBD. Anticancer Res 2007; 27: 3749-56. 
12 Schmetterer KG, Pickl WF. The IL-10/STAT-3 axis: Contributions to immune tolerance by thymus and peripherally-derived regulatory T-cells. Eur J Immunol 2017; 47: 1256-65.

13 Actis GC, Pellicano R. The pathologic galaxy modulating the genotype and phenotype of inflammatory bowel diseases: comorbidity, contiguity, and genetic and epigenetic factors. Minerva Med 2016; 107: 401-12.

14 Wehkamp J, Salzman NH, Porter E et al. Reduced Paneth cell alpha-defensins in ileal Crohn's disease. PNAS (USA) 2005; 102: 18129-134.

15 Mosca S, Bottino V, Camera A. Acute self-limited colitis complicating diagnostic colonoscopy. Am J Gastroenterol 2001; 96: 1669-1670.

16 Holtmann MH, Galle PR. Current concepts of pathophysiological understanding and natural course of ulcerative colitis. Langenbecks Arch Surg 2004; 389: 341-9.

17 Hendriksen C, Kreiner S, Binder V. Long-term prognosis in ulcerative colitis - based on results from a regional patient group from the county of Copenhagen. Gut 1985; 26: 158-63.

18 Gomollón F, Dignass A, Annese V et al. 3rd European Evidence-based Consensus on the Diagnosis and Management of Crohn's Disease 2016: Part 1: Diagnosis and Medical Management. J Crohns Colitis 2017; 11 : $3-25$.

19 Preiss JC, Zeitz M. Use of methotrexate in patients with IBD. Clin Exp Rheumatol 2010; 28: S151-5.

20 Feagan BG, Rochon J, Fedorak RN et al. Methotrexate for the treatment of Crohn's Disease. New Engl J Med 1995; 332: 292-7.

21 Van Dieren J, Kuipers E, Samsom J, Nieuwenhuis EE, van der Woude CJ. Revisiting the immune modulators tacrolimus, methotrexate, and mycophenolate mofetil: their mechanisms of action and role in the treatment of IBD. Inflamm Bowel Dis 2006; 12: 311-27.

22 Te HS, Schiano TD, Kuan SF, Hanauer SB, Conjeevaram HS, Baker AL. Hepatic effects of long-term methotrexate use in the treatment of IBD. Am J Gastroenterol 2000; 95: 3150-60.

23 Nobel Foundation. Autobiography of Gertrude B Elion, the Nobel Prize in Physiology or Medicine, 1988. Oncologist 2006; 11: 966-8.

24 Sahasranaman S, Howard D, Roy S. Clinical pharmacology and pharmacogenetics of thiopurines. Eur J Clin Pharmacol 2008; 64: 753-67.

25 Bean RH. The treatment of chronic ulcerative colitis with 6-mercaptopurine. Med J Aust 1962; 49: 592-3.

26 Hawthorne AB, Logan RF, Hawkey CJ et al. Randomized controlled trial of azathioprine withdrawal in ulcerative colitis. BMJ 1992; 305: 20-2. 
27 Present DH, Korelitz BI, Wisch N, Glass JL, Sachar DB, Pasternack BS. Treatment of Crohn's disease with 6MP. A long-term, randomized, double-blind study. New Engl J Med 1980; 302: 981-7.

28 Axelrad JE, Roy A, Lawlor G, Korelitz B, Lichtiger S. Thiopurines in IBD: Current evidence and historical perspectives. World J Gastroenterol 2016; 22: 10103-17.

29 Gargallo CJ, Lué A, Gomollón F. Biosimilars in inflammatory bowel disease. Minerva Med 2017; 108: $239-54$.

30 Mahadevan U. Medical treatment of ulcerative colitis. Clin Colon Rectal Surg 2004; 17: 7-19.

31 Ben-Horin S, Goldstein I, Fudim E et al. Early preservation of effector functions followed by eventual T-cell memory depletion: a model for the delayed onset of the effects of thiopurines. Gut 2009; 58: 396-403.

32 Cosnes J, Bourrier A, Lahare D et al. Early administration of azathioprine vs conventional management of Crohn's disease: a randomized controlled trial. Gastroenterology 2013; 145: 758-65.

33 Panes J, Lopez-Sanroman A, Bermejo F et al. Early azathioprine therapy is no more effective than placebo for newly diagnosed Crohn's Disease. Gastroenterology 2013; 145: 766-74.

34 Marshall JK, Otley AR, Waqqas Afif et al. Canadian Association of Gastroenterology position statement regarding the use of thiopurines for the treatment of IBD. Can J Gastroenterol Hepatol 2014; 28: 371-2.

35 Actis GC, Fadda M, Pellicano R, David E, Rizzetto M, Sapino A. The 17-yr single-center experience with the use of azathioprine to maintain remission in ulcerative colitis. Biomed Pharmacother 2009; 63: 362-5.

36 Cassinotti A, Actis GC, Duca P et al. Maintenance treatment with azathioprine in ulcerative colitis: outcome and predictive factors after drug withdrawal. Am J Gastroenterol 2009; 104: 2760-7.

37 Actis GC, Pellicano R, Rosina F. 6-MP for azathioprine intolerant IBD: Literature search and reappraisal of own data. Inflamm Allergy Drug Targets 2015; 14: 133-7.

38 Actis GC, Rosina F. Out-patient care for IBD at a primary referral hospital in Turin. Minerva Gastroenterol Dietol 2010; 56: 27-34.

39 Eriksson C, Rundquist S, Cao Y, Montgomery S, Halfvarson J. Impact of thiopurines on the natural history and outcome of ulcerative colitis: a cohort study. Gut 2018; epub ahead of print [PMID: 29618498 DOI: 10.1136/gutjnl-2017-315521]

40 Margagnoni G, Fasci-Spurio F, Feigusch L, Koch M, Papi C, Aratari A. Long-term course of UC in the prebiologic era. A retrospective study in a tertiary level Center. Minerva Gastroenterol Dietol 2014; 60: $275-83$.

41 Saibeni S, Virgilio T, D'Incà R et al. The use of thiopurines for the treatment of inflammatory bowel diseases in clinical practice. Dig Liver Dis 2008; 40: 814-20. 
42 Fraser AG, Orchard TR, Jewell DP. The efficacy of azathioprine for the treatment of IBD: a 30-yr experience. Gut 2002; 50: 485-9.

43 Bardhan KD, Simmonds N, Royston C, Dhar A, Edwards CM, Rotherham IBD Database Users Group. A UK IBD database: making the effort worthwhile. J Crohn's Colitis 2010; 4: 405-12.

44 Kirchgesner J, Lemaitre M, Rudnichi A et al. Therapeutic management of inflammatory bowel disease in reallife practice in the current era of anti-TNF agents: analysis of the French administrative health databases 20092014. Aliment Pharmacol Ther 2017; 45: 37-49.

45 Allen PB, Olivera P, Emery P et al. Review article: Moving towards common therapeutic goals in Crohn's disease and rheumatoid arthritis. Aliment Pharmacol Ther 2017; 45: 1058-72.

46 Colombel JF, Rheinisch W, Mantzaris GJ et al. Randomized clinical trial: deep remission in biologic and immunomodulator naïve patients with Crohns disease - A SONIC post-hoc analysis. Aliment Pharmacol Ther 2015; 41: 734-46

47 Prieux- Klotz C, Nahon S, Amiot A et al. Rate and predictors of mucosal healing in UC treated with thiopurines: Results of a multicentric cohort study. Dig Dis Sci 2017; 62: 473-80.

48 Actis GC, Pellicano R, David E, Sapino A. Azathioprine, mucosal healing in UC, and the chemoprevention of colitic cancer: A clinical-practice-based forecast. Inflamm Allergy Drug Target 2010; 9: 6-9

49 Gong J, Zhu L, Guo Z et al. Use of thiopurines and risk of colorectal neoplasia in patients with inflammatory bowel disease: a meta-analysis. PLoS One 2013; 8: e811487.

50 Eriksson C, Cao Y, Rundquist S et al. Changes in medical management and colectomy rates; a population-based cohort study on the epidemiology and natural history of ulcerative colitis in Örebro, Sweden. Aliment Pharmacol Ther 2017; 46: 748-57.

51 Korelitz BI. Enduring value of thiopurines for inflammatory bowel disease therapy. Dig Dis Sci 2017; 62: 292 3.

52 Kansen HM, vanRheenen PF, Houwen RHJ et al. Less anti-infliximab antibody formation in pediatric Crohn's patients on concomitant immune modulators. J Pediatr Gastroenterol Nutrition 2017; 65: 425-9.

53 Dart RJ, Irving PM. Optimizing use of thiopurines in inflammatory bowel disease. Exp Rev Clin Immunol 2017; 13: $877-88$

54 Kennedy NA, Kalla R, Warner B et al. Thiopurine withdrawal during sustained clinical remission in IBD: relapse and recapture rates, with predictive factors in 237 patients. Aliment Pharmacol Ther 2014; 40: 1313-23. 
55 Park MS, Kim DH, Kim DH et al. Leukopenia predicts remission in patients with IBD and Behçet on thiopurine maintenance. Dig Dis Sci 2015; 60: 195-204.

56 Setshedi M, Epstein D, Winter TA, Myer L, Watermeyer G, Hift R. Use of thiopurines in IBD is associated with an increased risk of non-melanoma skin cancer in an at-risk population: a cohort study. J Gastroenterol Hepatol 2012; 27: 385-9.

57 Colombel JF, Panaccione R, Bossuyt P et al. Effect of tight control management on Crohn's disease (CALM): a multicentre, randomised, controlled phase 3 trial. Lancet 2018; 390: 2779-2789. 